\title{
Multi-Objective Sizing of Battery Energy Storage Systems for Stackable Grid Applications
}

Arias, Nataly Banol; Lopez, Juan Camilo; Hashemi, Seyedmostafa; Franco, John F.; Rider, Marcos J.

Published in:

IEEE Transactions on Smart Grid

Link to article, DOI:

10.1109/TSG.2020.3042186

Publication date:

2021

Document Version

Peer reviewed version

Link back to DTU Orbit

Citation (APA):

Arias, N. B., Lopez, J. C., Hashemi, S., Franco, J. F., \& Rider, M. J. (2021). Multi-Objective Sizing of Battery Energy Storage Systems for Stackable Grid Applications. IEEE Transactions on Smart Grid, 12(3), 2708 - 2721. https://doi.org/10.1109/TSG.2020.3042186

\section{General rights}

Copyright and moral rights for the publications made accessible in the public portal are retained by the authors and/or other copyright owners and it is a condition of accessing publications that users recognise and abide by the legal requirements associated with these rights.

- Users may download and print one copy of any publication from the public portal for the purpose of private study or research.

- You may not further distribute the material or use it for any profit-making activity or commercial gain

- You may freely distribute the URL identifying the publication in the public portal 


\title{
Multi-Objective Sizing of Battery Energy Storage Systems for Stackable Grid Applications
}

\author{
Nataly Bañol Arias, Member, IEEE, Juan Camilo López, Member, IEEE, Seyedmostafa Hashemi, Member, IEEE, \\ John F. Franco, Senior Member, IEEE, and Marcos J. Rider, Senior Member, IEEE.
}

\begin{abstract}
The deployment of battery energy storage systems (BESS) is rapidly increasing as a prominent option to support future renewable-based energy systems. However, despite its benefits from a technical perspective, there are still challenges related to its economic viability. On the other hand, sizing BESS considering only their economic viability can be impractical because financial objectives could be in conflict with other aspects, such as battery degradation and grid impact. This paper proposes a multi-objective approach to determine the optimal size of BESS providing stackable services, such as frequency regulation and peak shaving. The proposed optimization method comprises financial and technical aspects represented by the payback period, battery life span, and grid impact. Given a set of market rules, a cost-benefit function, a regulation signal, consumption profiles and grid data, an enumerative approach is adopted to provide a set of Pareto optimal solutions. The performance of the proposed method is validated using the regulation market structure from PJM interconnection. Furthermore, a real 240-node distribution grid is used to assess the grid impact via OpenDSS. Simulations demonstrate that the proposed approach is a flexible and practical decision-making tool that investors can exploit when designing new BESS.
\end{abstract}

Index Terms-Battery energy storage systems, frequency regulation, Pareto optimality, peak shaving, stackable services.

\section{INTRODUCTION}

B ATTERY energy storage systems (BESS) have been recently pointed out as a prominent option to support the power grid by providing different global and local ancillary services. BESS can serve multiple purposes, such as renewable energy integration [1], frequency regulation [2], demand response [3], peak shaving [4], energy arbitrage [5], upgrade deferral [6], and voltage support [7] due to their flexibility and fast response capabilities. For this reason, investments in new BESS are becoming of interest to many stakeholders, from independent system operators, regional transmission organizations, distribution system operators (DSOs) and private investors, such as market-based entities, utility companies, or end customers. BESS can provide several services, which can be adjusted to the necessities of each owner. However,

This work was supported by the Brazilian institution FAPESP grants No. 2018/23617-7, 2019/01906-0, 2017/21752-1, and 2015/21972-6.

N. Bañol Arias, J. C. López and M. J. Rider are with Department of Energy Systems, School of Electrical and Computing of Engineering, University of Campinas (UNICAMP), Campinas, São Paulo, Brazil. E-mails: \{mnbanol, jclopeza, mjrider\}@unicamp.br;

S. Hashemi is with the Center for Electric and Energy, Department of Electrical Engineering, Technical University of Denmark, 2800 Kgs. Lyngby, Denmark. E-mail: shtog@elektro.dtu.dk

J. F. Franco is with School of Energy Engineering, São Paulo State University (UNESP), Rosana, São Paulo, Brazil. E-mail: j.f.franco@ieee.org. despite the multiple applications of BESS, there is still a major concern related to their economic viability [8]. The capital costs are directly proportional to the physical size and power management system of the storage unit, i.e., the battery and the converter. Therefore, grid applications that amortize the initial BESS investment and justify their usage are required.

Market participation is an option to recover the capital costs by collecting revenue from power or energy services. In that regard, frequency regulation is one of the most profitable services [9]. BESS are suitable for frequency regulation because they can react quickly to on-line regulation signals. Furthermore, since energy conversion is based on power electronics and microprocessor-based controllers, their operation can be optimized on-site to competently support such service. Another way to justify the usage of BESS is quantifying their benefits to the grid operation. When properly managed, BESS can provide power to the grid during on-peak periods, helping to alleviate congestion and voltage issues in both transmission and distribution networks [10]. It avoids network upgrades in the short-term and, in a long-term, it provides grid investment deferral, which would be of interest for DSOs. Additionally, different services can be combined aiming at increasing the profitability of the BESS, which are also referred in the literature as stackable services [11], [12]. Few studies have addressed the combination of BESS applications with different objectives, such as frequency regulation and energy arbitrage, reserve, and regulation [13]-[18]. However, most of the studies remain on techno-economic assessments without optimally sizing the BESS.

An important aspect when defining the size of BESS is that each grid application requires different BESS configurations related to its energy and power capacity. For instance, peak shaving and energy arbitrage require high energy capacity whereas frequency regulation requires high power capacity to increase the power bids [19]. Thus, larger and more expensive converters will elevate the chances of the BESS's owner to participate in the regulation market, but at the expense of high (or even unfeasible) capital costs. Hence, the size and operation of BESS should be co-optimized.

On the other hand, high energy exchange and oscillations may reduce the BESS's life span [20]. Regulation signals are unpredictable and noisy, and peak shaving requires deep charging and discharging cycles, both of which are causes of battery degradation. This important aspect is commonly overlooked among studies that address BESS sizing due to of the complexity of its calculation. Finally, BESS connected at the distribution level have an impact on the grid. Such impact 
Table I

Comparison of the Proposed Method with Previous Approaches

\begin{tabular}{|c|c|c|c|c|c|c|c|c|c|c|}
\hline Ref. & $\begin{array}{c}\text { Solution } \\
\text { Method }^{+}\end{array}$ & Purpose* & $\begin{array}{c}\text { Multiobjective } \\
\text { Approach }\end{array}$ & $\begin{array}{l}\text { Stackable } \\
\text { Services }\end{array}$ & $\begin{array}{c}\text { Initial } \\
\text { Investment }\end{array}$ & $\begin{array}{c}\text { Grid } \\
\text { Impact }\end{array}$ & $\begin{array}{c}\text { Battery } \\
\text { Degradation }\end{array}$ & Profit & $\begin{array}{c}\text { Payback } \\
\text { Period }\end{array}$ & $\begin{array}{c}\text { Real Distribution } \\
\text { System Data }\end{array}$ \\
\hline$[21]$ & Simulations & FR & & & $\checkmark$ & & & $\checkmark$ & & \\
\hline [22] & Simulations & RES & & & & & $\checkmark$ & & & \\
\hline [23] & LP/MPC & RES & & & $\checkmark$ & & $\checkmark$ & $\checkmark$ & & \\
\hline [24] & MISOCP & RM & & & & $\checkmark$ & & & & \\
\hline [25] & Simulations & FR & & & & & & & & \\
\hline [26] & DP & FR & & & $\checkmark$ & & & $\checkmark$ & & \\
\hline$[27]$ & Simulations & FR & & & $\checkmark$ & & & & & \\
\hline [28] & Simulations & FR & & & $\checkmark$ & & & $\checkmark$ & & \\
\hline [29] & Decomposition & EA,FR & & & $\checkmark$ & & $\checkmark$ & & & \\
\hline$[30]$ & LP & RM,FR,EA & & $\checkmark$ & $\checkmark$ & & $\checkmark$ & $\checkmark$ & & \\
\hline [31] & Neural networks & RES & & & $\checkmark$ & & & & & \\
\hline [32] & Neural networks & RES & & & $\checkmark$ & & & & & \\
\hline [33] & MPC & EA,RES & & & $\checkmark$ & $\checkmark$ & $\checkmark$ & $\checkmark$ & & \\
\hline [34] & MPC & RES & & & $\checkmark$ & & & & & \\
\hline [35] & Simulations & GS & $\checkmark$ & & $\checkmark$ & $\checkmark$ & $\checkmark$ & & & \\
\hline [36] & MISOCP & GS & $\checkmark$ & & $\checkmark$ & $\checkmark$ & & & & \\
\hline [37] & Simulations & FR & $\checkmark$ & & $\checkmark$ & & & $\checkmark$ & & \\
\hline Proposed method & Enumerative & FR, PS & $\checkmark$ & $\checkmark$ & $\checkmark$ & $\checkmark$ & $\checkmark$ & $\checkmark$ & $\checkmark$ & $\checkmark$ \\
\hline
\end{tabular}

can be beneficial or detrimental, depending on the size of the BESS, the location, and the nature of each grid application. Depending on the type of BESS investor, assessing the grid impact could be useful. For instance, DSOs, who have close access to grid data, would be concern with the power quality of their grids. On the other hand, assessing the grid impact could be useful in collaborative arrangements between private BESS investors and their electricity service providers. Most of the research involving grid applications from BESS disregards grid impact mainly because it requires a large number of power flow calculations and data [24].

Another important aspect that should be considered when sizing the BESS is the discretization of the decision variables, i.e., battery and converter capacities. From a mathematical point of view, it could make sense to consider the decision variables as integers. However, those variables should have a level of discretization that is compatible with commercial BESS solutions.

\section{A. Literature review and research contributions}

Several studies have focused on sizing BESS for frequency regulation [21], [25]-[28]. A procedure based on adjustable state-of-charge (SOC) limits for the optimal sizing and operation of BESS participating in regulation markets and operating in an isolated power system, is proposed in [21]. In [25], a method to define the power and energy required for achieving the targeted system inertia and power/frequency characteristics is proposed. The method in [25] disregards the economic (capital costs or profits) and degradation aspects of the problem. A different approach is presented in [26], in which a twolevel profit-maximization strategy for planning and controlling BESS participating in regulation markets is proposed. The authors demonstrated that the optimal BESS control consists of charging and discharging the battery around a target SOC. This idea is later adopted in this paper as part of the strategy that guides the BESS operation when it is not providing services.

Iterative-based methods proposed in [27] and [28] take into account economic criteria and they work based on a performance score for regulation market participation. The methods in [27] and [28] employ an iterative procedure that chooses an initial power rate and capacity, and the initial performance scores are calculated. Then, these values are increased iteratively until the best performance score is considered as the optimal solution.

On the other hand, works presented in [22], [23], [31], [32], develop methods for sizing BESS to provide RES integration support. Three sizing and control heuristic algorithms are proposed in [22]. In [23], an algorithm based on linear programming is proposed to obtain the optimal BESS sizing parameters (capacity and power rate) to optimize the participation of an existing photovoltaic (PV) power plant in electricity markets. A similar approach is presented in [31], in which the optimal size of a PV-BESS system is obtained to participate in one hour-ahead and day-ahead markets is addressed through a feed-forward neural network. A neural network approach is also used in [32] to determine the BESS size for RES integration support. While [22] and [23] account for degradation aspects, only [23], [31], and [32] consider economic aspects in the optimization process.

Some works have studied the BESS sizing problem to provide various services via BESS, e.g., frequency regulation and energy arbitrage [29], energy arbitrage and renewable energy source integration [33]. However, the BESS sizing problem considering the stackability of services has been barely explored in the specialized literature [30]. Authors in [29] propose a method based on primal decomposition and sub-gradient cutting-planes to solve the problem of placing and sizing BESS to jointly participate in energy and reserve markets. The proposed approach uses a rate of return to ensure profitability. Energy arbitrage, frequency regulation, and reserve via BESS are also addressed in [30], in which an optimization framework based on linear programming is proposed to simultaneously optimize BESS size, BESS market participation, and BESS life span. Even though, it comprises economic and degradation aspects, the impact on the grid is disregarded. Moreover, a model predictive control (MPC) 
method is proposed in [33] to optimize the participation of BESS in real and day-ahead markets and to maximize the profit of the combined BESS and wind farm operation. The optimization carries out a two-stages process, in which the BESS size is defined in the first stage, and the second stage it defines the daily operation of the BESS. The proposed method considers the impact of the BESS operation in the transmission network through a voltage sensitivity analysis, which differs from our proposed approach that focuses on the distribution network. A similar two-stage stochastic MPC is proposed in [34] to determine the optimal size and operation of BESS. The method uses a single-objective function that aims at minimizing the overall generation and storage costs without considering the provision of stacked services. Moreover, authors in [34] disregarded battery degradation and revenue aspects.

Additionally, multi-objective and single-objective MPC methods have been proposed for peak shaving and BESS energy management [38]-[40]. The method proposed in [38], manages the BESS dispatch in several grid-connected microgrids to reduce their electricity costs. Similarly, an MPC method is proposed in [40] to provide peak shaving via BESS for a household with a PV system in a rural distribution grid using a single-objective function. A different approach is proposed in [39], in which the proposed MPC method considers the minimization of two objectives: degradation rate of BESS and efficiency of the microgrid operation. Even though [38]-[40] address topics related to BESS management/control via MPC methods, these works have different purposes than those of optimal BESS sizing.

On the other hand, a multi-objective method to size BESS for grid support is proposed in [35], in which two objectives are minimized: energy losses at the distribution grid and the total investment costs, including distributed generation units and BESS, via an elitist non-dominated sorting genetic algorithm-II (NSGA-II). A similar proposal is presented in [36], where mixed-integer second-order cone programming is used to formulate the problem. Both [35] and [36] disregard the provision of stacked services, and only [35] accounts for battery lifespan aspects. Similar multi-objective approaches for optimally sizing of BESS have been proposed in recent literature. However, purposes are different to those addressed in this work, e.g., reducing microgrid operation costs [41], [42], or improving microgrid resilience [43]. Other studies have used multi-objective optimization for battery management and/or control purposes, e.g., optimal dispatch of storage units, microgrid's energy management systems, minimization of electricity costs, among others, without necessarily sizing the BESS [44]-[47]. One important aspect that should be highlighted is that most of the previous works that address BESS sizing do not pay attention to the discretization of the BESS variables, i.e., battery and converter capacities. While authors in [33] and [45] use BESS size variables with a level of discretization more compatible with commercial solutions, some works use continuous variables to represent the problem [34], [40], [41], and others use small discretization steps, (e.g., $0.5 \sim 1 \mathrm{kWh} / \mathrm{kW}$ ) [35], [39], [42], [44], [46], [47], which may not be practical and result in high computational complexity.
Table I summarizes the reviewed literature, including the aspects discussed above. Most of the works in Table I calculate the initial investments within the objective function, while only a few consider battery degradation and grid impact. Furthermore, the concept of stackable services has been scarcely studied in the specialized literature. Note that a multi-objective approach that optimizes the size of BESS, considering the conflict between financial and technical objectives, such as payback period, life span, and grid impact has yet to be proposed. In response to this gap, and as an extension of the previous work in [37], this paper proposes a flexible and efficient method for optimizing the size of BESS for stackable grid applications: frequency regulation and peak shaving. The proposed optimization method employs an exhaustive and enumerative search that consists of evaluating all combinations of the state variables (i.e., battery size, converter size, and objective SOC). Given historical frequency and load consumption measurements, historical ancillary service prices, a set of market rules, an investment cost function, and distribution grid data; this approach provides a set of Pareto optimal solutions. It is a suitable decision-making tool that helps pondering the trade-off between conflicting objective functions via Pareto optimality. The main contributions of this paper are twofold:

1) A flexible multi-objective approach to define the optimal size of BESS providing multiple grid applications, individually and simultaneously (a.k.a., stackable services), co-optimizing capital costs, payback period, battery life span, and grid impact. The proposed methodology obtains solutions (i.e., battery and converter capacities) with a flexible level of discretization that can realistically represent the BESS sizing problem.

2) A new method to assess the grid impact caused by the size and operation of the BESS in distribution systems. Results are validated using data from an existing distribution network and real load-consumption profiles obtained from smart-meters in [48].

Note that the proposed method is flexible because it can be adjusted to the interests and the available information of the BESS investor.

The remaining part of the paper is organized as follows: Section II presents the multi-objective approach to solve the BESS sizing problem and describes the objective functions; Section III describes the grid applications from BESS and the optimization procedure; Section IV shows the simulation results, followed by the conclusions and future work described in Section V.

\section{Multi-ObJective Approach}

Defining the optimal size of BESS is a challenging task due to conflicting nature of the objectives: BESS with large storage capacity and converters would increase the benefits from participating in power or energy markets. However, it would lead to unrealistic capital costs. Moreover, large BESS can be programmed to reduce consumption during peak hours; nevertheless, if the operation of the BESS is governed by more lucrative purposes (e.g., frequency regulation), it could cause overloading and/or voltage issues at the distribution grid. On 
the other other, battery life span is always in conflict with financial goals. Thus, if the battery reaches its end of life very quickly, it would be a barrier for capital recovery. In order to deal with these conflicts, this paper proposes a multi-objective approach that considers three objectives: i) payback period (representing financial aspects); ii) battery life span; and iii) grid impact; the last two representing physical and technical aspects.

\section{A. Payback Period}

The payback period corresponds to the time required to recover capital investments. It is calculated as a function of the capital costs and the market participation revenue:

1) Capital Costs: Capital costs are usually related to the physical characteristics of the storage unit, i.e., energy capacity $\left(E_{\max }\right)$, in $\mathrm{kWh}$, and the nominal power of the converter $\left(P_{\max }\right)$, in $\mathrm{kW} . E_{\max }$ is proportional to the physical size and the cost of the storage units. $P_{\max }$ is related to the power management system and power electronics used by the BESS. Thus, the initial investment of BESS is given by the cost function (1), where $E_{\max }$ and $P_{\max }$ are investment decision variables. Variables $\lambda^{\text {bat }}$ and $\lambda^{\text {ch }}$ correspond to the energy and power part of the costs associated with the battery pack (cells, modules, battery management system), the balance of system hardware (cooling system, containerization, controller, converter), and the engineering, procurement and construction costs. Since the proposed optimization method is an enumerative and nonanalytical process, cost function $C^{\text {cost }}(\cdot)$ does not need to be a smooth analytical function.

$$
C^{\text {cost }}=f\left(\lambda^{\text {bat }}, \lambda^{\text {ch }}, E_{\max }, P_{\max }\right)
$$

2) Market Participation Revenue: It corresponds to the revenue received by the BESS owner due to grid-service provision. Regulation markets and the mechanics used to remunerate market participants change drastically according to each transmission system operator (TSO). Here, the proposed enumerative procedure is adapted to optimize the BESS size in the context of the frequency regulation market of Pennsylvania-New Jersey-Maryland (PJM) Interconnection [49]. Nevertheless, it is worthy to highlight that the proposed approach can be adapted to other contexts. In the PJM market, frequency regulation is remunerated based on the regulation power capacity and a performance score index, which assesses the market participant's response to the frequency signals sent by the TSO [50]. The market participant should submit bids on hourly basis following a set of market rules that will be explained in Section III-A. Under this framework, the market participation revenue is calculated using (2), in which, $P_{h}^{\text {bid }}$ is the regulation power capacity per hour, in $\mathrm{MW}, \lambda_{h}$ is the capacity clearing price, in $\$ / \mathrm{MW}$, and $\delta$ is the performance index.

$$
M^{\mathrm{rev}}=\sum_{h} P_{h}^{\mathrm{bid}} \cdot \lambda_{h} \cdot \delta
$$

After calculating capital costs and market revenue with (1) and (2), it is possible to calculate the payback period, which is represented by $f_{1}$ and given by (3).

$$
f_{1}=Y^{-}+\frac{\left|-C^{\mathrm{cost}}+\sum_{y=1}^{Y^{-}} M_{y}^{\mathrm{rev}}(1+i)^{y}\right|}{M_{(y+1)}^{\mathrm{rev}}(1+i)^{(y+1)}}
$$

where, $Y^{-}$is the last year with negative cumulative cash flow; the second term represents the cumulative net cash flow at the end of the year $Y^{-}$, and the denominator term is the total cash inflow during the year following year $Y^{-} . M^{\text {rev }}$ is increased along time according to the inflation rate $i$ [51].

\section{B. Battery Life Span Assessment}

Assessing battery degradation is a complex process that depends on several factors, such as the storage technology, state of charge (SOC), depth of discharge (DOD), temperature, charging rate, among others. Cycle life models are commonly used for battery degradation assessment [52]. They calculate the expected life of the battery based on the number of charging/discharging cycles. In this paper, the cycle life of the BESS is estimated using the semi-logarithmic function $\mathcal{C} \mathcal{L}_{\text {DOD }}=\left(\mathrm{L}_{100}\right) e^{\alpha(1-\mathrm{DOD})}$ proposed in [53], which provides the number of cycles as a function of the DOD. In this function $L_{100}$ represent the number of cycles at $100 \%$ DOD and $\alpha$ is a coefficient decay obtained from experimental data. Hence, it is necessary to identify the number of cycles the BESS performs at specific DODs. For this purpose, the rainflow cycle counting algorithm [54] is used, which is widely accepted in the literature for battery cycle studies [55]. This algorithm only requires the yearly SOC pattern as an input.

Since the cycle life curve is non-linear, it can be discretized in small DOD intervals (e.g., 0\%-10\%, 10\%-20\%, .., 90\%$100 \%)$. Then, the number of cycles for each DOD interval is calculated with the rainflow algorithm. Finally, the total degradation is represented by $f_{2}$, given by (4), in which $\bar{\Gamma}$ is the maximum capacity fade of the BESS before end-of-life (representing the reduction percentage of the original energy capacity), and $\mathrm{NC}_{\mathrm{DOD}}$ is the number of cycles at a specific DOD.

$$
f_{2}=\sum_{\mathrm{DOD}} \frac{\bar{\Gamma} \cdot \mathrm{NC}_{\mathrm{DOD}}}{\mathcal{C} \mathcal{L}_{\mathrm{DOD}}}
$$

\section{Grid Impact Assessment}

The grid impact caused by the operation of the BESS can be assessed through different power-quality indicators, e.g., voltage and current imbalances, line loading, voltage profile, among others. In this case, energy losses are a suitable indicator of grid impact in distribution systems because, on one hand, reducing power losses automatically improves voltage profiles and reduces overloading in transformers and circuits. On the other hand, they quantify the amount of dissipated energy that does not produce any real work [11]. In this paper, the grid impact is assessed by the percentage variation of the energy losses with and without BESS. A real three-phase distribution system, including yearly load profiles obtained from smart-meters, is used to demonstrate the impact of the BESS [48]. The energy losses are calculated in hourly basis using an exact AC power flow via OpenDSS [56]. As shown in 
(5), the objective function $f_{3}$ is written in terms of the energy losses with the BESS $\left(E_{h}^{l s s}\right)$ and without the BESS $\left(E_{h}^{l s s^{*}}\right)$. Positive values of $f_{3}$ represent an increase of the energy losses whereas negative values represent a decrease.

$$
f_{3}=\sum_{h} \frac{\left(E_{h}^{\mathrm{lss}}-E_{h}^{\mathrm{lss}^{*}}\right)}{E_{h}^{\mathrm{lss}^{*}}} \cdot 100 \%
$$

It is worth mentioning that, if the investment decision corresponds to an investor who has limited access to distribution grid information, the grid impact could be easily disregarded from the proposed algorithm without affecting its deployment. Thus, the BESS size will be driven by the economic and degradation criteria. Note that (3)-(5) are calculated on a yearly basis and their corresponding units are different.

\section{GRID APPLICATIONS FROM BESS}

The grid applications for the optimal sizing of BESS are introduced in this section as separated case studies.

\section{A. Case A: Sizing of BESS for frequency control}

Frequency regulation is a grid application to obtain revenues from market participation [13]. The application of frequency control differs from market to market. However, most markets are based on the same principle: the TSO collects the power capacity bids from the market participants and, based on those bids and the current frequency signal, the TSO sends an automatic power request to each one of the participants in a second-to-second basis. In the PJM's regulation market, the following rules must be implemented [49]:

1) market participants should submit their bids every hour, containing the amount of regulation power capacity and an offer price;

2) since the market is cleared every hour, the bids need to be submitted up until 65 minutes prior to the operating hour;

3) power bids must be made in multiples of $0.1 \mathrm{MW}$ and the minimum amount is $0.1 \mathrm{MW}$; and

4) power bids must be symmetric (i.e., the regulation capacity should be equal for both, up and down regulation,

The symmetric offering demands that the BESS can inject or consume the same amount of offered power into the system during a specific timeframe. The fulfillment of the symmetric condition will depend on the BESS capacity and its SOC moments before the market clearance.

When BESS participate in the regulation market, the charging and discharging actions are governed by the regulation signals. Due to the highly fluctuating and uncertain behavior of the regulation signal, it is possible that, at some point, the BESS will reach its upper or lower limits (i.e., be fully charged or fully discharged) hindering the fulfillment of the market rules, (e.g., symmetric offers or minimal power bid). In that case, if the BESS owner decides to participate in the next regulation period, it is likely to get a fine or even be banned from the market. An alternative would be to "leave" the market and to implement a mechanism that restores the SOC at a value that allows the BESS to participate in the next

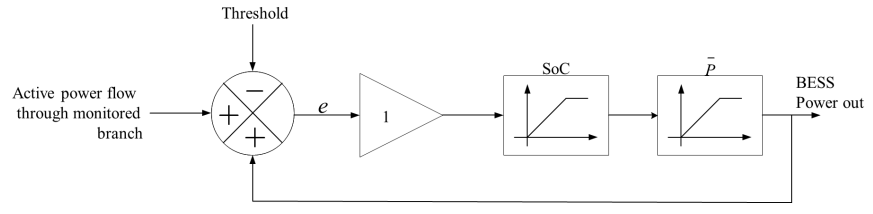

Fig. 1. BESS peak-shaving control strategy.

regulation period. Thus, a practical operation strategy called objective SOC is proposed. The purpose of the objective SOC strategy (denoted by $\mathrm{SoC}_{\mathrm{obj}}^{*}$ ) is to guide the control actions that the BESS must deploy when it is unable to symmetrically offer more than $0.1 \mathrm{MW}$ in the next hour. Then, instead of offering any power bid, the strategy will allow the charge/discharge of the BESS at maximum rate until it reaches the $\mathrm{SoC}_{\mathrm{obj}}^{*}$.

\section{B. Case B: Sizing of BESS for Peak Shaving}

Peak shaving is a grid application that uses BESS to dislocate net consumption from the peak period to other hours of the day when congestion is low [13]. As discussed in Section II-C, peak shaving is an effective strategy to improve the grid impact of BESS. Similar to the regulation case, peak shaving also requires a strategy to govern the daily operation of the BESS, which is described below:

In the early morning, when there is no congestion, the BESS is charged up to $80 \%$ of its capacity. Out of this period, the BESS is ready to provide peak shaving. According to the BESS operator requirements, a fixed threshold is set $a$ priori to trigger the peak-shaving control strategy. Thus, the BESS performs peak shaving during the periods when the net active power flowing through the monitored branch overpasses the threshold, following the proportional integral control (PI) depicted in Fig. 1. Otherwise, the BESS remains idle until its next charging period (i.e., 1:00 of the next day).

Attention must be taken to avoid fully charging or discharging the battery. Moreover, BESS configurations are only acceptable if at least $90 \%$ of the peaks have been shaven along the year. Otherwise, the solution is considered unfeasible.

It is worth noting that performing peak shaving via BESS brings many technical benefits, such as grid investment deferral and RES integration support that can be of interest to TSOs and DSOs, and energy arbitrage and congestion management, which can be of interest to private investors. These are technical advantages, whose economic benefits are not easy to quantify, mainly because there are no market incentives. Even in cases in which an economic benefit can be determined (e.g., reduction of the electricity bill), it is usually insignificant when compared to benefits obtained for providing frequency regulation [17]. Therefore, from an economic pointof-view, peak shaving is a service that does not produce significant revenue, which may result in impractical payback periods. For this reason, and for this particular Case B, $f_{1}$ is only related to the capital costs in (1).

\section{Case C: Sizing of BESS for Stackable Services}

The BESS is optimally sized in this case to provide stackable services: frequency regulation and peak shaving. To do 
so, the BESS is set to perform peak shaving during peak periods, i.e., when the demand overpasses its threshold, and to perform regulation in the remaining time of the day, as long as the regulation service does not provoke new peaks. Moreover, the BESS is always set to charge in the early morning, i.e., between 01:00 and 05:00, in order to avoid new peaks and to be prepared for the rest of day. The participation of the BESS in the regulation market depends on the current SOC and the conditions previously discussed in Section III-A. Furthermore, the BESS follows the same operation strategies previously discussed for each separated service.

Note that in the absence of nodal load profiles, local load profiles could be used for assessing peak-shaving or stackable applications, disregarding the effect of the grid impact in the BESS sizing solution.

\section{Optimization Procedure}

In this section, the proposed enumerative search method used to optimize the size of the BESS is described and the multi-objective nature of the problem is characterized by the set of optimal Pareto solutions, a.k.a. non-dominated solutions, obtained at the end of the optimization process.

\section{A. Enumerative Optimization Method}

Three parameters need to be determined to co-optimize all objectives: the energy capacity of the BESS $\left(E_{\max }^{*}\right)$, the power rate of the converter $\left(P_{\max }^{*}\right)$, and the objective $\mathrm{SOC}\left(\mathrm{SoC}_{\mathrm{obj}}^{*}\right)$. The flowchart of the proposed enumerative procedure is shown in Fig. 2. The operation of the BESS is executed for every time interval $\Delta_{t}$ in a year, according to each application: peak shaving, regulation or stackable service.

The input parameters of the proposed enumerative procedure are the historical frequency regulation signal $f^{\text {hist }}$, the historical load consumption $L^{\text {hist }}$ at each node, the historical regulation prices $\lambda^{\text {hist }}$, the grid parameters, the minimum and maximum energy capacities for the $\operatorname{BESS}(\underline{E}$ and $\bar{E})$, and the minimum and maximum power capacity of the converter $(\underline{P}$ and $\bar{P})$. These limits are based on technical or financial criteria, or due to the technologies at hand. Other parameters that must be selected within the algorithm are the scale (i.e., granularity) of the discrete steps used to enumerate the set of possible storage capacities $\Delta_{\mathrm{E}}$, nominal power of the converter $\Delta_{\mathrm{P}}$, and the objective SOC $\Delta_{\mathrm{SoC}}$.

It should be mentioned that the BESS size depends on the chosen discretization scheme since it defines the search space of the problem. Therefore, the smaller the discretization is, the more detailed the results of the non-dominated solutions will be, at the expense of increasing the time required to obtain the Pareto optimal solutions. In some cases, the discrete steps do not need to be too small. For instance, there will be no significant difference in terms of investment and overall operation between a $1.00 \mathrm{MWh} / 1.00 \mathrm{MW}$ BESS and another with 1.01 MWh/ 1.01 MW. Thus, discrete steps of $\Delta_{\mathrm{E}}=0.01 \mathrm{MWh}$, and $\Delta_{\mathrm{P}}=0.01 \mathrm{MW}$ would be too small to be practical. That kind of criteria should be taken into account when choosing the discretization steps.

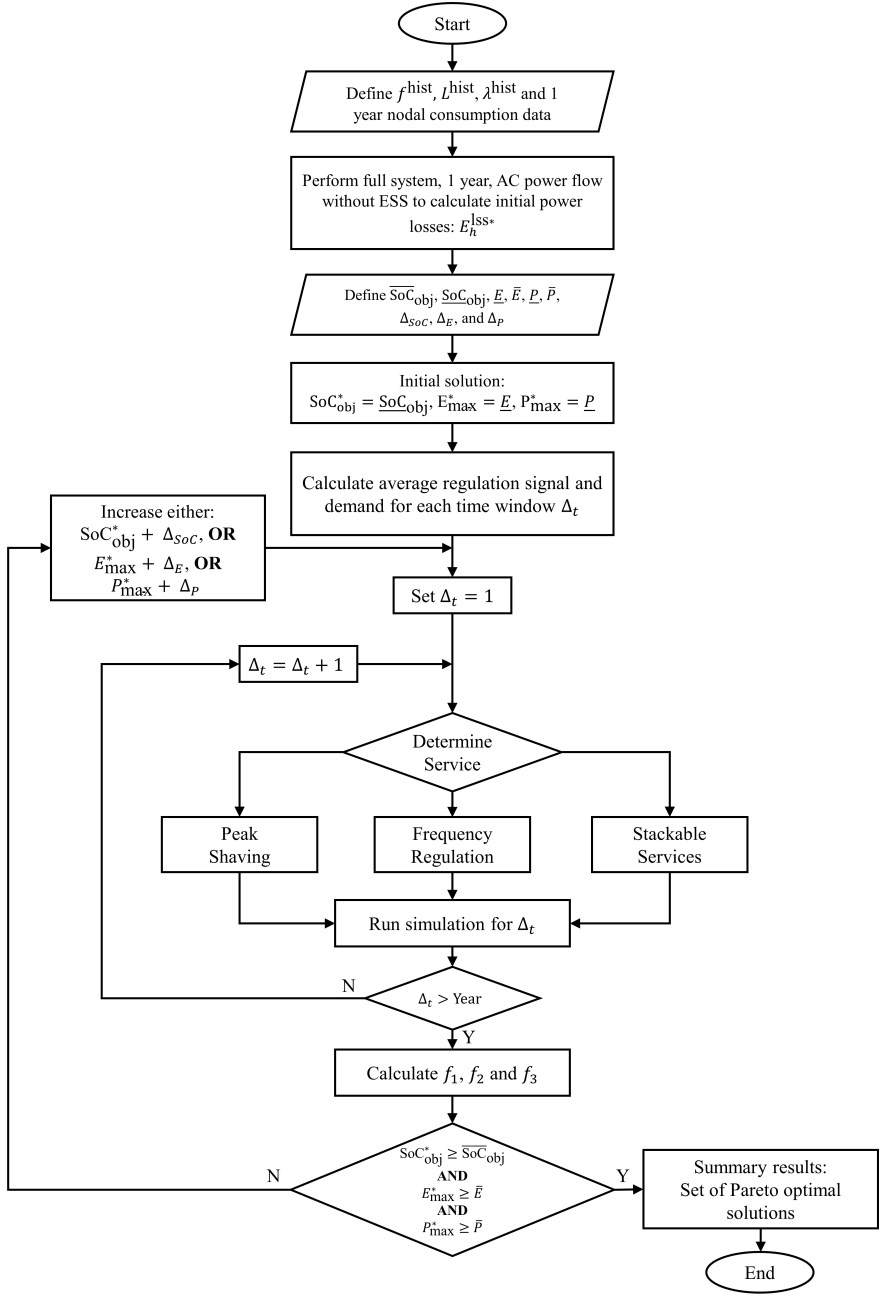

Fig. 2. Flowchart of the proposed enumerative optimization method.

Note that, there are only three variables enumerated in Fig. 2 and, considering that the granularity of the enumeration sets does not need to be too small, the performance of the optimization procedure is acceptable in terms of modern standard computational resources. The proposed enumerative procedure will update the set of Pareto optimal solutions for each selected value of $E_{\max }^{*}, P_{\max }^{*}$ and $\mathrm{SoC}_{\mathrm{obj}}^{*}$ of the current solution, and the values of the three objective functions.

\section{B. Set of Pareto Optimal Solutions}

A Pareto optimal solution or non-dominated solution is a solution in which none of the objective functions can be improved without degrading the quality of the others. The procedure to obtain the set of non-dominated solutions consists on comparing the objective functions of each solution with the others. Whenever a solution is dominated by another one, it is removed from the set of non-dominated solutions and the process resumes. Note that the proposed enumerative optimization method is a straightforward and generalized strategy to optimize the BESS size. Hence, the proposed method can be easily adapted to any given regulation market, capital cost function or battery degradation function. It is worth mentioning that when solving multi-objective problems, different types 


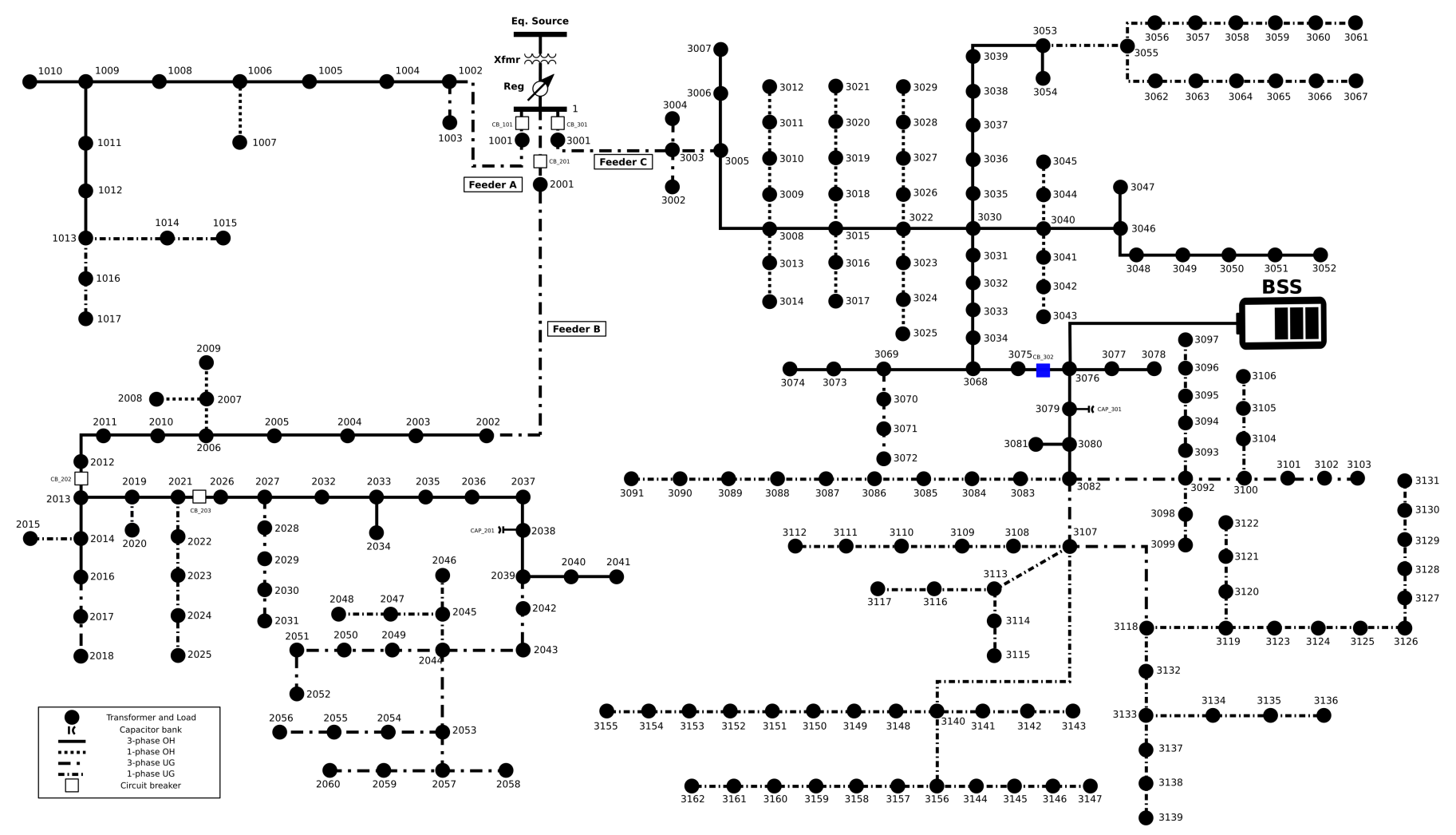

Fig. 3. Real 240-node three-phase distribution system [48].

of Pareto curves may be obtained, e.g., convex, concave, or discontinuous. According to the shape of the curves, some methods could be used to select the best compromise solution based on particular interests of the decision-maker.

\section{Simulations And Results}

The proposed methodology has been tested using historical regulation signals reported by the PJM interconnection [57], considering one full year (2018). The corresponding historical prices were taken from the PJM market [58] in which regulation signals have a resolution of one sample every two seconds. However, in attempt to reduce the computational burden, the simulations are executed every six minutes taking the corresponding mean value of the regulation signal. The convention adopted for the regulation signal is negative when regulation up is required (discharging mode) and positive when regulation down is required (charging mode).

The real 240-node three-phase distribution system shown in Fig. 3 has been used to run tests. It is a radial network formed by three feeders at $69 \mathrm{kV}$ and comprises several smart-meters installed at each load point, allowing full grid observability. Each black circle represents a MV distribution transformer. For all cases, the BESS has been installed at node 3076 from Feeder C, considering three-phase connection. The fixed threshold of the peak-shaving is set at $1000 \mathrm{~kW}$. The monitored branch of the BESS peak-shaving control strategy is the circuit breaker CB_302. Fig. 4 shows the active power flow trough CB_302 for one year of data. Yearly load-consumption profiles with hourly-based measurements are taken from the smart-

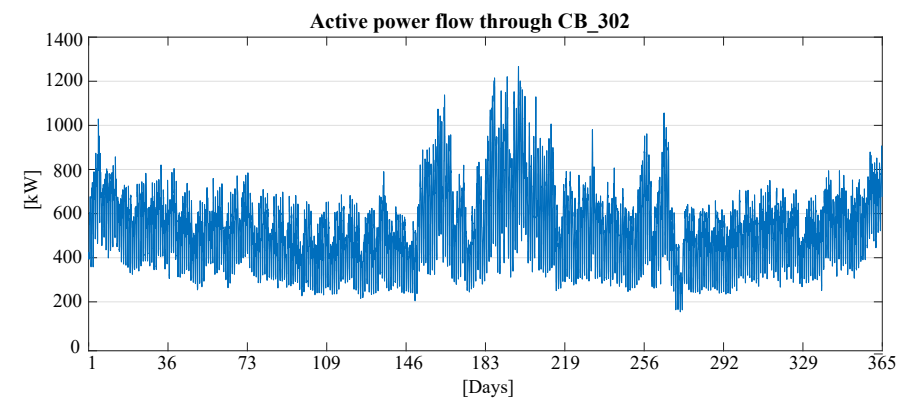

Fig. 4. Yearly active power flow through branch CB_302.

meter data and used to assess the grid impact of the BESS. Further details of the distribution system can be found in [48].

Since BESS have fast response, it is expected that it follows the regulation signal almost perfectly, for which the performance index $\delta$ is considered as unitary. The battery pack and balance of the system hardware costs are $345 \mathrm{USD} / \mathrm{kWh}$ and $245 \mathrm{USD} / \mathrm{kW}$, respectively [59] and the inflation rate is $2 \%$. The parameters used in the battery degradation calculations are taken from [53], and the energy capacity fade $(\bar{\Gamma})$ is defined as $20 \%$ considering $80 \%$ as the battery's end-of-life. The discretization scheme is based on the following definitions: $\underline{E}=100 \mathrm{kWh}, \bar{E}=2000 \mathrm{kWh}, \underline{P}=100 \mathrm{~kW}, \bar{P}=1000 \mathrm{kWh}$, $\Delta_{E}=100 \mathrm{kWh}, \Delta_{P}=100 \mathrm{~kW}$ and $\Delta_{\mathrm{SoC}}=0.1$. The overall system operation is validated through the software OpenDSS that executes the three-phase unbalanced AC power flow calculations. The simulations of the BESS operation are implemented in Matlab and the results are analyzed using the study cases described in Section III. 
Case A

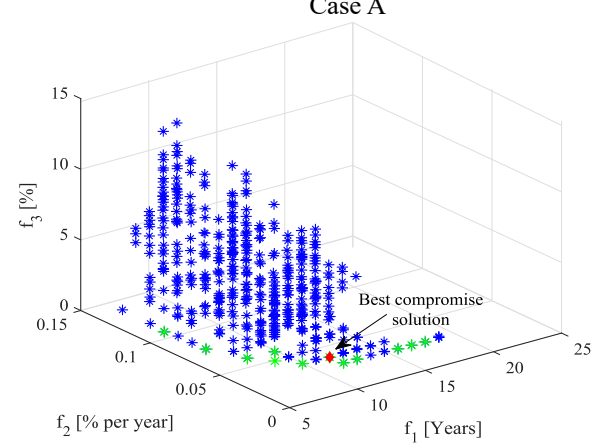

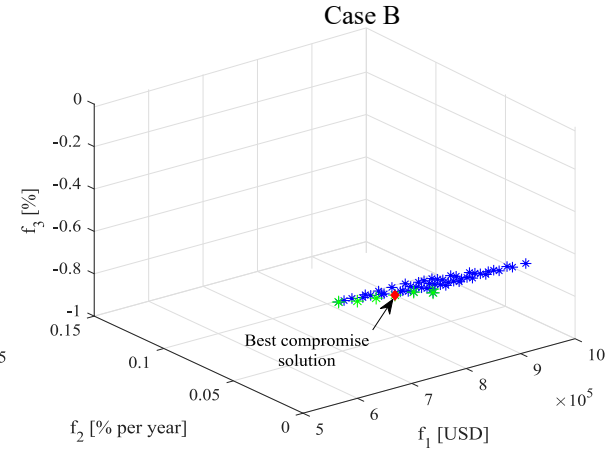

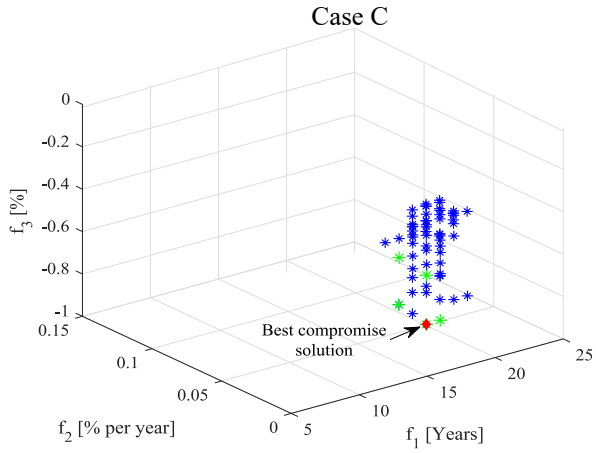

Fig. 5. General (blue stars) and non-dominated solutions (green stars) for Case A: Regulation; Case B: Peak shaving; Case C: Stackable services.

\section{A. Pareto Optimal Solutions and Best Compromise Solution}

Fig. 5 shows the sets of general solutions (blue stars) and Pareto optimal or non-dominated solutions (green stars) for Cases A, B, and C. Solutions in Case A (frequency regulation) are more numerous, whereas solutions in Case $\mathrm{B}$ and $\mathrm{C}$ (with peak shaving) are scarcer. This happens because the proposed method will only accept solutions with $90 \%$ peak-shaving efficiency. A more detailed analysis of the BESS operation can be performed after selecting a best compromise solution from the set of Pareto optimal solutions. The best compromise solution is a solution that satisfies a particular preference (qualitative or quantitative) of the decision-maker. There are several methods, such as analytic hierarchical process (AHP) [60], the gradient-based method (which only works for convex Pareto fronts), $\epsilon$-perturbation method, min-max, goal programming [61], and fuzzy approach [62], which can be adapted to choose a compromise solution from a Pareto curve. The chosen method will depend on the characteristics of the Pareto front and the level of involvement of the decision-maker [35].

The best compromise solution (highlighted with the red diamond in Fig. 5) is here selected using a centroid-based method, which is a systematic way to pick a solution that represents a fair balance among the three objective functions. This method is suitable when the decision-maker does not have a bias for any of the three objectives, or if he/she does not have a fourth decision criterion that can be used to select the final answer [35]. The process is described as follows: a) solutions are normalized to obtain values between 0 and $1 ; b$ ) the Euclidean norm for each solution is computed using the objective functions as coordinates; and c) the solution with the minimum euclidean norm is chosen as the best compromise solution.

The characteristics of the best compromise solution for each case are shown in Table II. Note that the size of the BESS in terms of battery capacity and converter is different for all cases. Cases B and C, involving peak-shaving, require BESS with higher battery capacity than the one for regulation in Case A. Note that for peak-shaving (Case B), the payback period $f_{1}$ is not calculated since the BESS owner does not get any significant revenue for this service. In this case, the BESS owner could be the DSO, since benefits in grid impact and lower degradation are obtained. As shown in Table II, grid impact is $-0.61 \%$ and $-0.90 \%$ for Cases B and C, i.e.,
Table II

Best COMPRomise SOLUTIONS FOR THE BESS SizING

\begin{tabular}{lccccccc}
\hline \hline & $\begin{array}{c}\text { Battery } \\
{[\mathrm{kWh}]}\end{array}$ & $\begin{array}{c}\text { Converter } \\
{[\mathrm{kW}]}\end{array}$ & $\begin{array}{c}\mathrm{SoC}_{\mathrm{obj}} \\
{[\%]}\end{array}$ & $\begin{array}{c}C^{\text {cost }} \\
{\left[10^{3} \mathrm{USD}\right]}\end{array}$ & $\begin{array}{c}f_{1} \\
{[\text { years }]}\end{array}$ & $\begin{array}{c}f_{2} \\
{[\% \text { per year }]}\end{array}$ & $\begin{array}{c}f_{3} \\
{[\%]}\end{array}$ \\
\hline Case A & 1000 & 100 & 50 & 369.5 & 10 & 0.02 & 1.33 \\
Case B & 1800 & 300 & - & 694.5 & - & 0.01 & -0.61 \\
Case C & 2000 & 400 & 40 & 788 & 18 & 0.03 & -0.90 \\
\hline \hline
\end{tabular}

energy losses were reduced almost $1 \%$ per year. Moreover, the degradation per year is very small, since peak-shaving has a lower impact on the battery lifespan than pure regulation. Cases $\mathrm{A}$ and $\mathrm{C}$ present the highest degradation (less than $0.03 \%$ per year) since the BESS is continuously charging or discharging according to the regulation signal. From the grid's perspective, the impact in Case A is detrimental, resulting in an increase in total energy losses of around $1.33 \%$. Results show that the peak shaving service (Case B) has the lowest degradation and good grid impact, reducing total energy losses in $0.61 \%$ per year. However, since there is no economic benefit from this service, the BESS investment is only justified by its benefit from a technical perspective.

The optimal BESS size found for stackable services (Case C) results in the most expensive solution with a battery of $2000 \mathrm{kWh}$ and a converter of $400 \mathrm{~kW}$. Furthermore, note that the value of the variable associated with the $\mathrm{SoC}_{\mathrm{obj}}$ is $40 \%$ (lower than Case A). In terms of degradation, Case $\mathrm{C}$ presents suitable results (only $0.03 \%$ per year). However, a large payback period of 18 years is observed. This large payback period is justified because there are long periods in which the BESS performs peak-shaving (without significant economic benefit), limiting its market participation. The above results demonstrate the unavoidable conflict between the objective functions, which justifies usage of multi-objective methodologies to optimize the sizing of BESS.

\section{B. Analysis of the BESS Operation During One Week}

1) Discussion for Case A: Fig. 6 shows the BESS operation during one week considering the best compromise solution for Case A. The regulation signal, the active power through the circuit breaker upstream the BESS (i.e., CB_302), the SOC of the BESS, and the total power losses are shown considering two scenarios: with and without BESS operation. Note that the frequency regulation signal is a random process. As a 

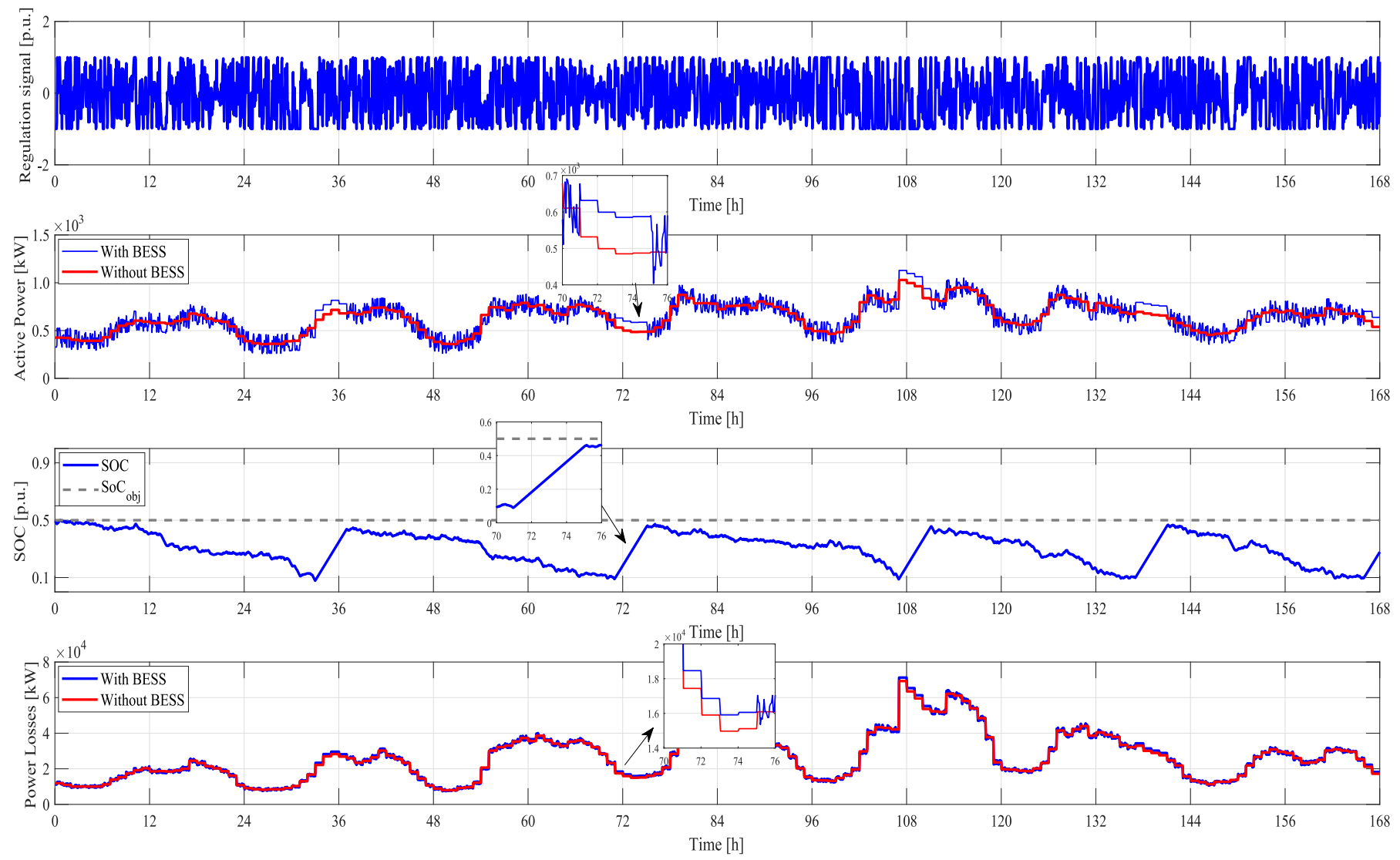

Fig. 6. Best compromise solution for Case A: BESS operation for one week.

consequence, with BESS, the active power flow through the circuit breaker CB_302 is also very fluctuating (in a range of $100 \mathrm{~kW}$ up and down, due to the rated power of the converter in Case A). However, there are some periods (e.g., between hours 31 and 37, 71 and 75, 107, and 111) in which the power flow is stable. Those periods correspond to the time in which the BESS "leaves" the market. As shown in Fig. 6, during these stable periods, the $\mathrm{SOC}$ increases constantly until the $\mathrm{SoC}_{\mathrm{obj}}$ is attained. In this simulation, the SOC rarely reaches values greater than 0.5 due to the frequency signal being mostly up regulation (i.e., discharging mode). Furthermore, it is worth noting that the converter efficiency is not unitary, making the discharging more prominent than the charging process. On the other hand, total power losses differ from both scenarios (with and without BESS), as shown in Fig. 6. A slight increase is perceived when the $\mathrm{SoC}_{\mathrm{obj}}$ is being recovered. Since the battery is only used to provide frequency regulation and not to improve the system operation, these results are acceptable.

2) Discussion for Case B: Similar results are depicted in Fig. 7 for the best compromise solution chosen for Case B, including the active power through the circuit breaker CB_302, the SOC, and the total power losses. When the BESS is not installed, there are many periods before midnight (between 18:00 and 22:00) and/or after midday (between 12:00 and 18:00) in which the power consumption is higher than the demand threshold, set as $1000 \mathrm{~kW}$. Fig. 7 shows that when the BESS is connected to the grid, the demand excess is successfully reduced most of the time, e.g., the peak observed between hours 110 and 119 is completely shaved. Furthermore, the BESS is able to shave the peak in consecutive hours. Since the peak shaving strategy accepts solutions with $90 \%$ peakshaving efficiency, there is a peak that is not shaved during its total duration as observed in Fig. 7 during hours 34 and 45. The peak is shaved until hour 42, when the minimum SOC is reached. After that, the BESS remains idle until the charging period in the next morning.

Note that the SOC changes according to the power flow at the circuit breaker CB_302. For instance, Fig. 7 shows that the battery charges to its maximum allowed SOC at the early mornings, e.g., between hours 48 and 53 to be prepared for the next peak event. Shortly after, there is a long period in the middle of the week in which the power does not overpass the threshold. Consequently, the BESS remains idle. Finally, active power losses are reduced when the BESS is discharging and slightly increase when it is charging.

3) Discussion for Case C: As shown in Fig. 8, there are many periods (e.g., hours 24-25, 40-41, and 108-116) in which the active power flow is stable for Case $\mathrm{C}$. This happens for two reasons: the BESS "leaves" the market (e.g., between hours 40 and 41), or the BESS is performing peak shaving (e.g., between hours 108 and 116). The rest of the time, the BESS is performing frequency regulation.

Note that, during the early morning, the BESS charges in preparation to perform both services (e.g., between hours 48 and 50,96, and 99), and it stops charging as soon as it is able to provide regulation. A particular situation is observed 

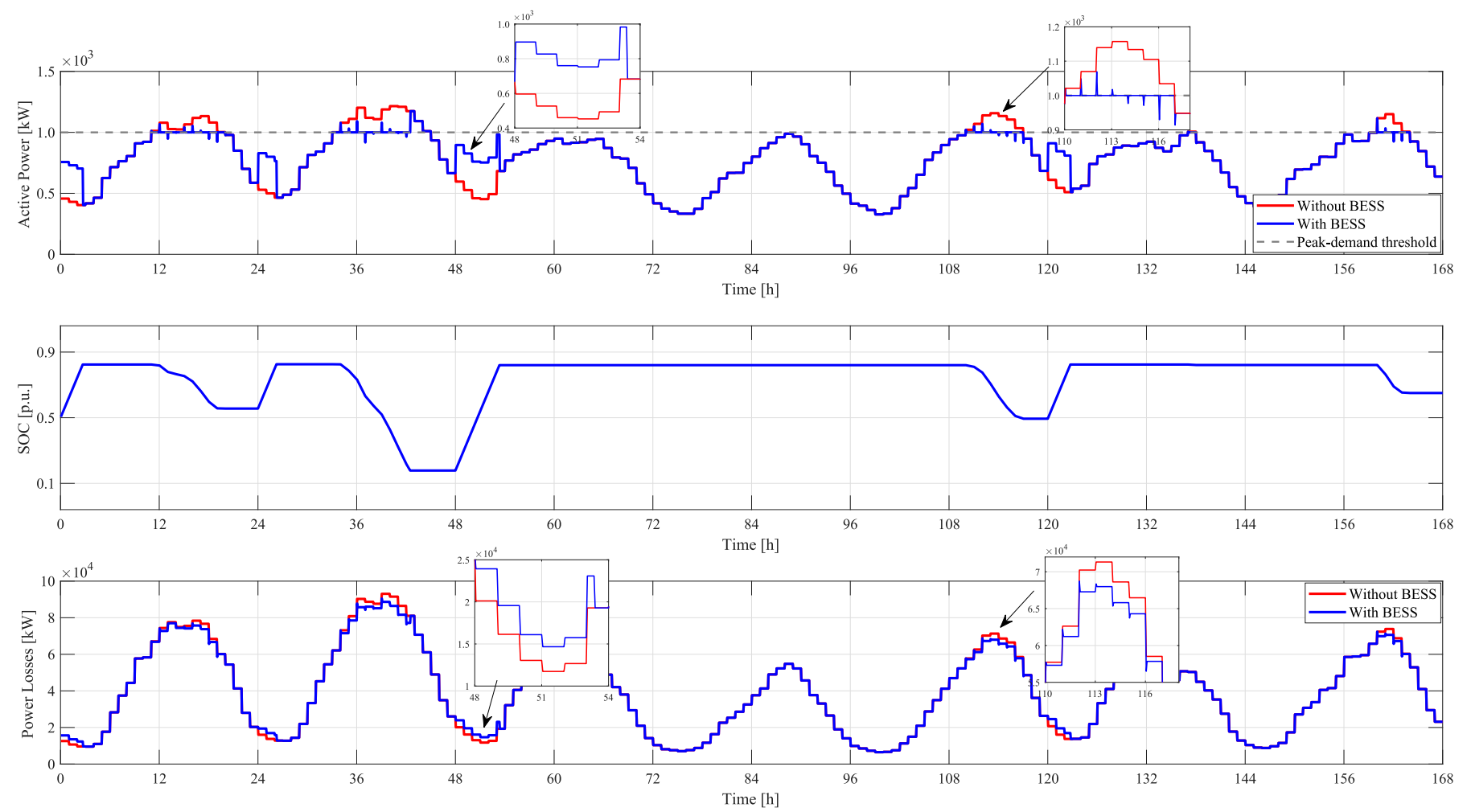

Fig. 7. Best compromise solution for Case B: BESS operation for one week.

in the early morning, during hours 74-76, in which the BESS is discharged until it reaches the $\mathrm{SOC}_{\mathrm{obj}}$. That occurred because the BESS was reaching its maximum capacity and the SOC has to be recovered to allows its participation in the market again. Moreover, after peak-periods, the BESS resumes frequency regulation depending on the current SOC and the peak-demand threshold. For instance, after the small peak observed between hours 108 and 116, the BESS remains idle because the demand is close to the threshold, limiting the regulation service. However, as soon as the demand decreases, the BESS is able to participate in the market (which occurs around hour 118) and performs regulation for approximately three hours. After that period, the BESS charges at a constant rate in preparation for a new cycle of services, and so on.

Finally, small variations of the active power losses are observed. As in the previous cases, the power losses are reduced when the BESS is performing peak shaving and slightly increase during the charging period or when performing regulation.

\section{Peak-shaving with Short-term Load Forecasting}

The peak-shaving control strategy used in Case B uses a fixed threshold that does not depend on the concurrent demand. Such method is suitable for congestion management in which a giving capacity limit is imposed beforehand and maintained fixed throughout the BESS operation. However, a more intelligent peak-shaving strategy would be the application of a dynamic threshold that changes according to the foreseeable demand. To do so, predictions of future demand are required, so that most peaks are shaved. In this subsection, the peak-shaving strategy from Case B has been upgraded using a short-term load forecasting method to define the dynamic threshold. The forecasting method was implemented using a simple auto-regressive function, trained with the yearly active power flow through branch CB_302 (see Fig. 4). After deploying the proposed enumerative optimization method, the best compromised solution for a BESS providing peak-shaving with dynamic threshold was a $1300 \mathrm{kWh} / 200 \mathrm{~kW}$ battery. In this case, $f_{1}=C^{\text {cost }}=497.5 \cdot 10^{3} \mathrm{USD}, f_{2}=0.26 \%$ and $f_{3}=-7.35 \%$. Fig. 9 shows the BESS operation during one week of the best compromised solution. Note that, everyday, the BESS discharges to flatten the demand and charges in the low congestion hours. Energy losses are lower than Case B, but the BESS suffers a more severe degradation. It is worth mentioning that having an efficient short-term forecasting method is not a simple (and sometimes achievable) task since it is highly dependent on the quality and the quantity of historical data used to train the forecasting method [63].

\section{Impact of the BESS Connection Node}

The proposed method is not designed to determine the best node for the connection of the BESS, since this would increase the number of state variables of the problem. Thus, the connection node is chosen a priori. Of course, the location directly impacts the values of $f_{1}, f_{2}$ and $f_{3}$ for each BESS configuration. Hence, changing the connection node would produce different BESS size results. To illustrate this, Table III shows the values of the three objective function for a $1800 \mathrm{kWh} / 300 \mathrm{~kW}$ BESS providing stackable services, located at different nodes of the main trunk at Feeder C. Note that, 

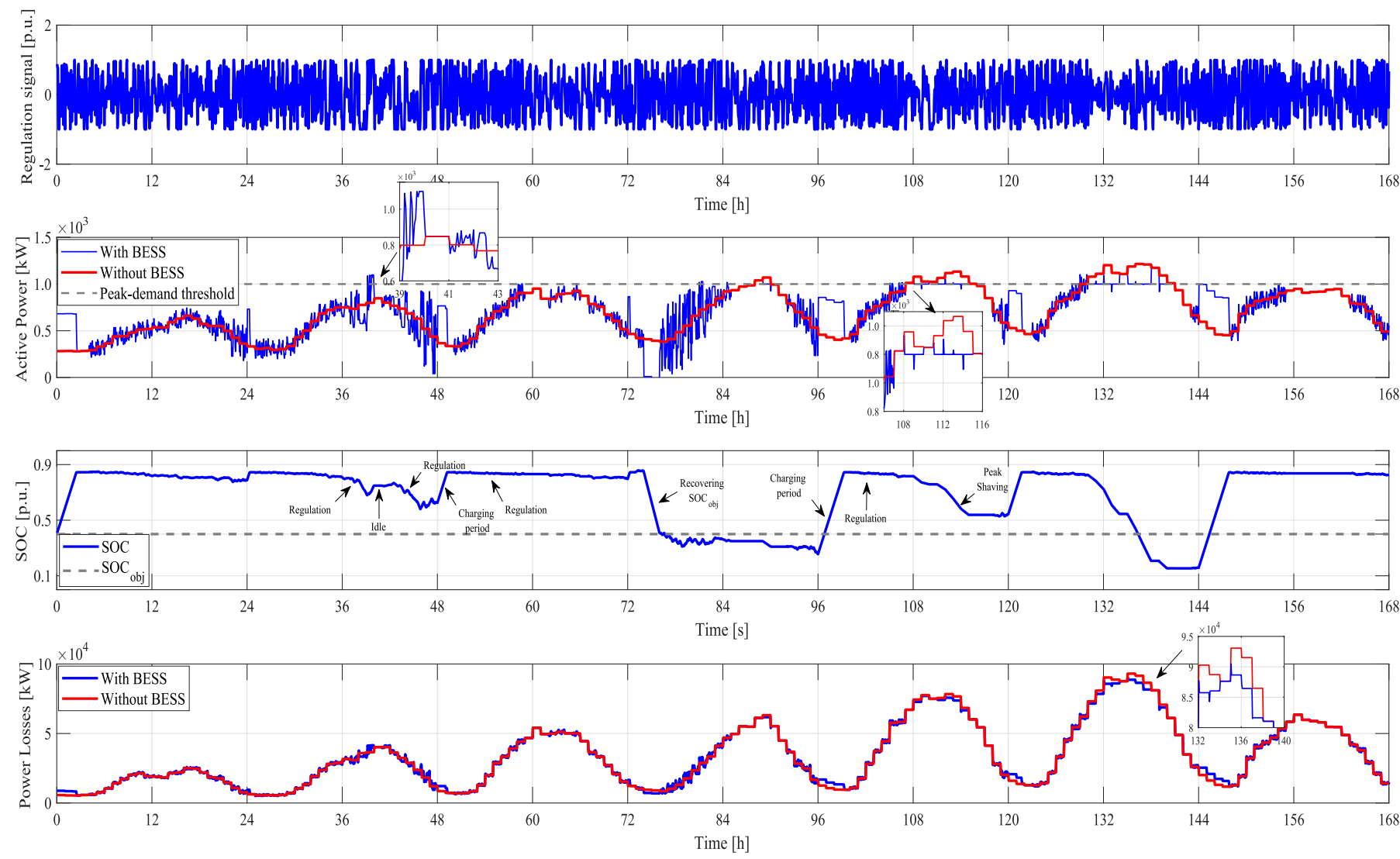

Fig. 8. Best compromise solution for Case C: BESS operation for one week.

Table III

VALUES of $f_{1}, f_{2}$, AND $f_{3}$ FOR A $1800 \mathrm{KWH} / 300 \mathrm{KW}$ BESS LOCATED AT DIFFERENT NODES OF THE MAIN TRUNK AT FEEDER C.

\begin{tabular}{cccc}
\hline $\begin{array}{c}\text { Location } \\
\text { Node }\end{array}$ & $\begin{array}{c}f_{1} \\
\text { [years] }\end{array}$ & $\begin{array}{c}f_{2} \\
\text { [\% per year] }\end{array}$ & $\begin{array}{c}f_{3} \\
{[\%]}\end{array}$ \\
\hline 3082 & 16 & 0.02 & -0.31 \\
3080 & 16 & 0.02 & -0.33 \\
3079 & 16 & 0.02 & -0.34 \\
3076 & 17 & 0.02 & -0.62 \\
3075 & 17 & 0.02 & -0.62 \\
3068 & 17 & 0.02 & -0.71 \\
3034 & 17 & 0.02 & -0.71 \\
3033 & 18 & 0.03 & -0.75 \\
3032 & 18 & 0.03 & -0.76 \\
3031 & 18 & 0.03 & -0.79 \\
3030 & 24 & 0.06 & -0.75 \\
3022 & \multicolumn{3}{c}{ - Infeasible - } \\
3015 & \multicolumn{3}{c}{ - Infeasible - } \\
3008 & \multicolumn{4}{c}{ - Infeasible - -} \\
3005 & \multicolumn{4}{|c}{} \\
\hline \hline
\end{tabular}

from node 3022 until 3005 solutions are infeasible because at least $90 \%$ of the peaks could not be shaven by that battery.

\section{E. Computational Time Analysis}

The proposed method requires simulating the operation of the BESS in one year. Thus, adopting a granularity of 10 samples per hour of data, the proposed method requires 87,600 simulations per BESS configuration, i.e., battery size, converter size, and objective SoC. The average time required to calculate the three objective functions is around 4.5 hours for each BESS configuration. A workstation with an Intel Core i7-6700 $3.41 \mathrm{GHz}$ processor and $8 \mathrm{~GB}$ of RAM was used to execute the tests. The average time may vary according to several factors, such as computer capabilities, granularity, and upper-lower limits; used to discretize the state variables. However, if fast solutions are required, the computational time could be strongly reduced through different strategies, such as granularity reduction, parallel computing, cloud computing and truncated Pareto solutions.

\section{Conclusions}

Given the opportunities and challenges arising from the deployment of battery energy storage systems (BESS) in power systems, this paper has proposed a multi-objective approach to determine their optimal size for multiple grid applications (e.g., frequency regulation and peak shaving). Conflicting objectives, including financial and technical aspects such as payback period, battery life span, and grid impact were cooptimized. The performance of the proposed optimization method was validated using historical regulation signals and ancillary service price data from the Pennsylvania-New JerseyMaryland market; the impact on the grid was assessed via OpenDSS using a real distribution network.

Results showed that the optimal size of the battery and the converter varies according to each grid application. For instance, the battery capacity for regulation and peak shaving is smaller than for stackable services. In contrast, the converter 

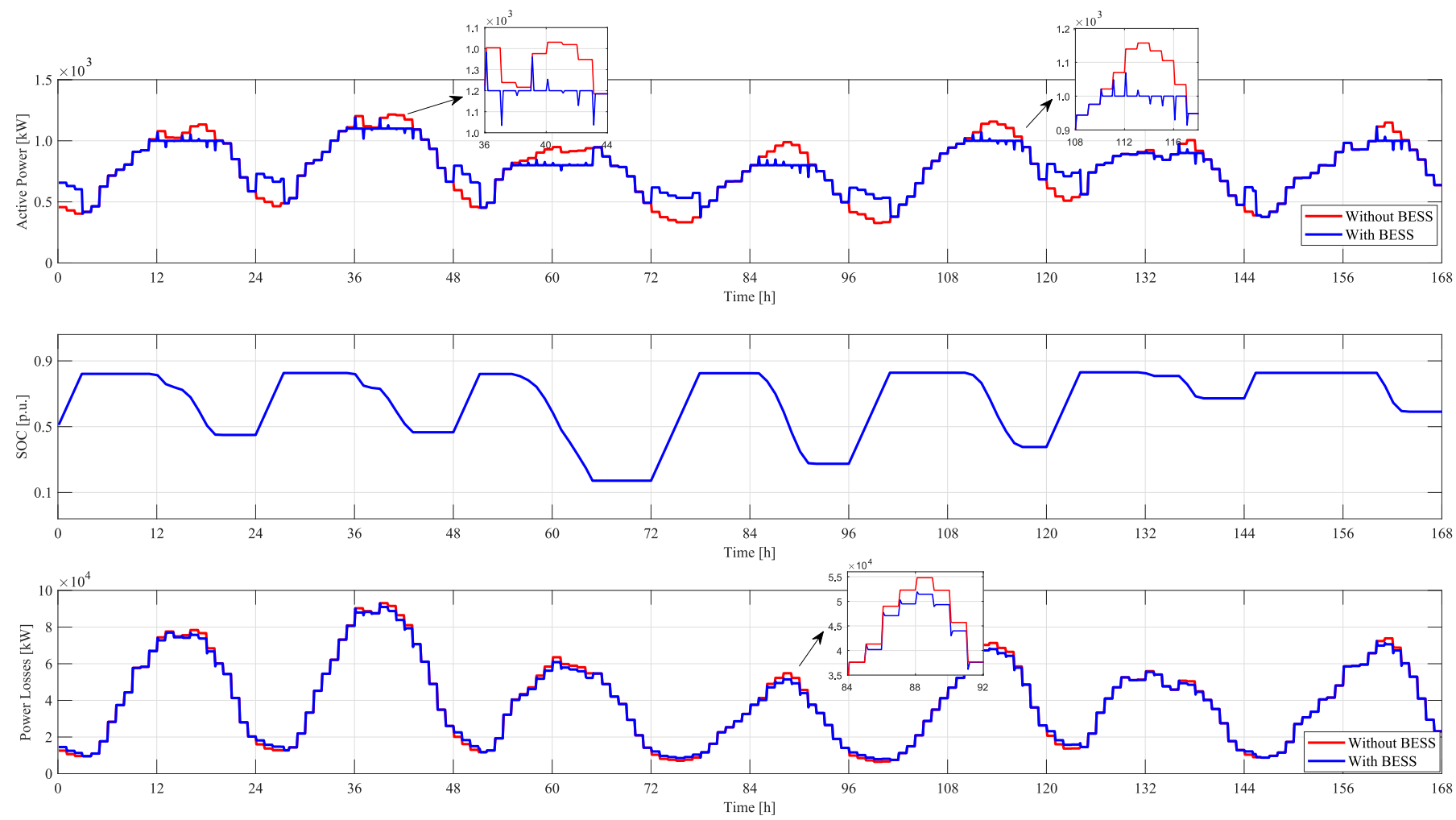

Fig. 9. Peak-shaving with dynamic threshold and short-term load forecasting: BESS operation for one week.

capacity is greater for regulation and peak shaving. Moreover, the objective state of charge changes according to each application. Results also showed that if the BESS is only used for regulation, the payback period is reasonable, but battery degradation and grid impact are detrimental. Contrarily, when the BESS is used for pure peak shaving, the improvement of the grid operation is noteworthy but the economic benefit has to be ignored. Finally, when the BESS is used for stackable grid applications, there is a high improvement on the distribution grid operation, at expense of a slightly worse payback period and an increase in the degradation. However, the payback period could be reduced if a market structure and a remuneration mechanism is developed for peak shaving. Moreover, advanced operation strategies could be developed to improve the life span of the battery and increase their viability in near future. However, due to the complexity of the problem, those strategies could be applied in a postoptimization stage, after the BESS is already sized. Lastly, aspects such as sizing BESS for renewable energy integration support, using forecasting to consider uncertainties in the regulation signal, and optimizing BESS location are of great interest for future research.

\section{REFERENCES}

[1] A. Nagarajan and R. Ayyanar, "Design and strategy for the deployment of energy storage systems in a distribution feeder with penetration of renewable resources," IEEE Trans. Sustain. Energy, vol. 6, no. 3, pp. 1085-1092, July 2015.

[2] J. Tan and Y. Zhang, "Coordinated control strategy of a battery energy storage system to support a wind power plant providing multi-timescale frequency ancillary services," IEEE Trans. Sust. Energy, vol. 8, no. 3, pp. 1140-1153, July 2017.
[3] Z. Wang, C. Gu, F. Li, P. Bale, and H. Sun, "Active demand response using shared energy storage for household energy management," IEEE Trans. Smart Grid, vol. 4, no. 4, pp. 1888-1897, Dec. 2013.

[4] Y. Yang, H. Li, A. Aichhorn, J. Zheng, and M. Greenleaf, "Sizing strategy of distributed battery storage system with high penetration of photovoltaic for voltage regulation and peak load shaving," IEEE Trans. Smart Grid, vol. 5, no. 2, pp. 982-991, Mar. 2014.

[5] Y. Dvorkin et al., "Ensuring profitability of energy storage," IEEE Trans. Power Syst., vol. 32, no. 1, pp. 611-623, Jan. 2017.

[6] D. M. Greenwood, N. S. Wade, P. C. Taylor, P. Papadopoulos, and N. Heyward, "A probabilistic method combining electrical energy storage and real-time thermal ratings to defer network reinforcement," IEEE Trans. Sustain. Energy, vol. 8, no. 1, pp. 374-384, Jan. 2017.

[7] J. Krata and T. K. Saha, "Real-time coordinated voltage support with battery energy storage in a distribution grid equipped with medium-scale PV generation," IEEE Trans. Smart Grid, vol. 10, no. 3, pp. 3486-3497, May 2019.

[8] D. A. Tejada-Arango, A. S. Siddiqui, S. Wogrin, and E. Centeno, "A review of energy storage system legislation in the US and the european union," Current Sustain./Renewable Energy Reports, vol. 6, no. 1, pp. 22-28, Mar. 2019.

[9] B. Zakeri and S. Syri, "Value of energy storage in the nordic power market - benefits from price arbitrage and ancillary services," in 13th Int. Conf. European Energy Market, Porto, Portugal, 2016, pp. 1-5.

[10] E. Telaretti and L. Dusonchet, "Battery storage systems for peak load shaving applications: Part 1: Operating strategy and modification of the power diagram," in IEEE 16th Int. Conf. on Environ. and Elect. Eng. (EEEIC), Florence, Italy, 2016, pp. 1-6.

[11] N. B. Arias, S. Hashemi, P. B. Andersen, C. Træholt, and R. Romero, "Distribution system services provided by electric vehicles: Recent status, challenges, and future prospects," IEEE Trans. Intell. Transp. Systems, vol. 20, no. 12, pp. 4277-4296, Dec. 2019.

[12] D. Parra and M. K. Patel, "The nature of combining energy storage applications for residential battery technology," Applied Energy, vol. 239, pp. 1343-1355, Apr. 2019.

[13] D. I. Karadimos et al., "Techno-economic analysis for optimal energy storage systems placement considering stacked grid services," in 14th Int. Conf. on the European Energy Market (EEM), Dresden, Germany, Jun. 2017, pp. 1-6. 
[14] D. Watson, C. Hastie, B. Gaudette, and M. Rodgers, "Demonstrating stacked services of a battery in a wind R\&D park," IEEE Trans. Power Syst., vol. 33, no. 2, pp. 1411-1419, Mar. 2018.

[15] E. Nasrolahpour, J. Kazempour, H. Zareipour, and W. D. Rosehart, "A bilevel model for participation of a storage system in energy and reserve markets," IEEE Trans. Sustain. Energy, vol. 9, no. 2, pp. 582-598, Apr. 2018.

[16] H. Khani and H. E. Z. Farag, "Joint arbitrage and operating reserve scheduling of energy storage through optimal adaptive allocation of the state of charge," IEEE Trans. Sustain. Energy, vol. 10, no. 4, pp. 17051717, Oct. 2019.

[17] Y. Shi, B. Xu, D. Wang, and B. Zhang, "Using battery storage for peak shaving and frequency regulation: Joint optimization for superlinear gains," IEEE Trans. Power Syst., vol. 33, no. 3, pp. 2882-2894, May 2018.

[18] J. Engels, B. Claessens, and G. Deconinck, "Optimal combination of frequency control and peak shaving with battery storage systems," IEEE Transactions on Smart Grid, 2019, to be published.

[19] M. B. C. Salles, J. Huang, M. J. Aziz, and W. W. Hogan, "Potential arbitrage revenue of energy storage systems in PJM," Energies, vol. 10, no. 1100 , pp. 1-19, July 2017

[20] B. Xu, J. Zhao, T. Zheng, E. Litvinov, and D. S. Kirschen, "Factoring the cycle aging cost of batteries participating in electricity markets," IEEE Trans. Power Syst., vol. 33, no. 2, pp. 2248-2259, Mar. 2018.

[21] P. Mercier, R. Cherkaoui, and A. Oudalov, "Optimizing a battery energy storage system for frequency control application in an isolated power system," IEEE Trans. Power Syst., vol. 24, no. 3, pp. 1469-1477, Aug. 2009.

[22] X. Ke, N. Lu, and C. Jin, "Control and size energy storage systems for managing energy imbalance of variable generation resources," IEEE Trans. Sustain. Energy, vol. 6, no. 1, pp. 70-78, Jan. 2015.

[23] A. Saez-de-Ibarra, A. Milo, H. Gaztañaga, V. Debusschere, and S. Bacha, "Co-optimization of storage system sizing and control strategy for intelligent photovoltaic power plants market integration," IEEE Trans. Sustain. Energy, vol. 7, no. 4, pp. 1749-1761, Oct. 2016.

[24] M. Qin, K. W. Chan, C. Y. Chung, X. Luo, and T. Wu, "Optimal planning and operation of energy storage systems in radial networks for wind power integration with reserve support," IET Gen., Trans. \& Dist., vol. 10, no. 8, pp. 2019-2025, May 2016.

[25] V. Knap et al., "Sizing of an energy storage system for grid inertial response and primary frequency reserve," IEEE Trans. Power Syst., vol. 31, no. 5, pp. 3447-3456, Sept. 2016.

[26] Y. J. A. Zhang, C. Zhao, W. Tang, and S. H. Low, "Profit-maximizing planning and control of battery energy storage systems for primary frequency control," IEEE Trans. Smart Grid, vol. 9, no. 2, pp. 712723, Mar. 2018

[27] S. Chen, T. Zhang, H. B. Gooi, R. D. Masiello, and W. Katzenstein, "Penetration rate and effectiveness studies of aggregated BESS for frequency regulation," IEEE Trans. Smart Grid, vol. 7, no. 1, pp. 167177, Jun. 2016.

[28] T. Zhang, H. Beng Gooi, S. Chen, and T. Goh, "Cost-effectiveness studies of the BESSs participating in frequency regulation," in IEEE Innovative Smart Grid Technology - Asia, Bangkok, Thailand, 2015, pp. $1-6$.

[29] B. Xu et al., "Scalable planning for energy storage in energy and reserve markets," IEEE Trans. Power Syst., vol. 32, no. 6, pp. 4515-4527, Nov. 2017.

[30] F. Sorourifar, V. M. Zavala, and A. W. Dowling, "Integrated multiscale design, market participation, and replacement strategies for battery energy storage systems," IEEE Trans. Sustain. Energy, vol. 11, no. 1, pp. 84-92, 2020.

[31] M. Brenna, F. Foiadelli, M. Longo, and D. Zaninelli, "Energy storage control for dispatching photovoltaic power," IEEE Trans. Smart Grid, vol. 9, no. 4, pp. 2419-2428, July 2018.

[32] T. K. A. Brekken, A. Yokochi, A. von Jouanne, Z. Z. Yen, H. M. Hapke, and D. A. Halamay, "Optimal energy storage sizing and control for wind power applications," IEEE Trans. Sustain. Energy, vol. 2, no. 1, pp. 6977, 2011.

[33] I. N. Moghaddam, B. Chowdhury, and M. Doostan, "Optimal sizing and operation of battery energy storage systems connected to wind farms participating in electricity markets," IEEE Trans. Sustain. Energy, vol. 10, no. 3, pp. 1184-1193, July 2019.

[34] K. Baker, G. Hug, and X. Li, "Energy storage sizing taking into account forecast uncertainties and receding horizon operation," IEEE Trans. Sustain. Energy, vol. 8, no. 1, pp. 331-340, 2017.

[35] K. Khalid Mehmood, S. U. Khan, S. Lee, Z. M. Haider, M. K. Rafique, and C. Kim, "Optimal sizing and allocation of battery energy storage systems with wind and solar power dgs in a distribution network for voltage regulation considering the lifespan of batteries," IET Renewable Power Gen., vol. 11, no. 10, pp. 1305-1315, 2017.

[36] M. Nick, R. Cherkaoui, and M. Paolone, "Optimal allocation of dispersed energy storage systems in active distribution networks for energy balance and grid support," IEEE Trans. Power Syst., vol. 29, no. 5, pp. 2300-2310, 2014

[37] N. B. Arias, R. Romero, J. C. López, and M. J. Rider, "Optimal sizing of stationary energy storage systems participating in primary frequency regulation markets," in IEEE PES Transm. Distrib. Conf. and Exhibition - Latin America (T\&D-LA), Lima, Peru, 2018, pp. 1-6.

[38] M. R. Sandgani and S. Sirouspour, "Priority-based microgrid energy management in a network environment," IEEE Trans. Sustain. Energy, vol. 9, no. 2, pp. 980-990, 2018.

[39] U. R. Nair and R. Costa-Castelló, "An analysis of energy storage system interaction in a multi objective model predictive control based energy management in dc microgrid," in 2019 24th IEEE Int. Conf. Emerging Technologies and Factory Automation (ETFA), 2019, pp. 739-746.

[40] D. Dongol, T. Feldmann, M. Schmidt, and E. Bollin, "A model predictive control based peak shaving application of battery for a household with photovoltaic system in a rural distribution grid," Sustain. Energy, Grids and Networks, vol. 16, pp. $1-13,2018$

[41] P. Xie, Z. Cai, P. Liu, X. Li, Y. Zhang, and D. Xu, "Microgrid system energy storage capacity optimization considering multiple time scale uncertainty coupling," IEEE Trans. Smart Grid, vol. 10, no. 5, pp. 5234 $5245,2019$.

[42] J. J. Kelly and P. G. Leahy, "Sizing battery energy storage systems: Using multi-objective optimization to overcome the investment scale problem of annual worth," IEEE Trans. Sustain. Energy, vol. 11, no. 4, pp. 2305-2314, 2020.

[43] B. Zhang, P. Dehghanian, and M. Kezunovic, "Optimal allocation of pv generation and battery storage for enhanced resilience," IEEE Trans. Smart Grid, vol. 10, no. 1, pp. 535-545, 2019.

[44] H. Farzin, M. Fotuhi-Firuzabad, and M. Moeini-Aghtaie, "A stochastic multi-objective framework for optimal scheduling of energy storage systems in microgrids," IEEE Trans. Smart Grid, vol. 8, no. 1, pp. 117127, 2017.

[45] Y. Li, Z. Yang, D. Zhao, H. Lei, B. Cui, and S. Li, "Incorporating energy storage and user experience in isolated microgrid dispatch using a multi-objective model," IET Renewable Power Gen., vol. 13, no. 6, pp. 973-981, 2019.

[46] W. L. Schram, T. AlSkaif, I. Lampropoulos, S. Henein, and W. G. J. H. M. van Sark, "On the trade-off between environmental and economic objectives in community energy storage operational optimization," IEEE Trans. Sustain. Energy, vol. 11, no. 4, pp. 2653-2661, 2020.

[47] M. R. Sandgani and S. Sirouspour, "Coordinated optimal dispatch of energy storage in a network of grid-connected microgrids," IEEE Trans. Sustain. Energy, vol. 8, no. 3, pp. 1166-1176, 2017.

[48] F. Bu, Y. Yuan, Z. Wang, K. Dehghanpour, and A. Kimber, "A timeseries distribution test system based on real utility data," in 2019 North American Power Symposium (NAPS), 2019, pp. 1-6.

[49] PJM - Forward Market Operations, PJM Manual 11: Energy \& Ancillary Services Market Operations, PJM, 2017.

[50] PJM - Dispatch, PJM Manual 12: Balancing Operations, PJM, 2019.

[51] R. Brealey, S. Myers, F. Allen, and P. Mohanty, Principles of Corporate Finance, 12th ed. McGraw-Hill Education, 2018.

[52] K. Smith, E. Wood, S. Santhanagopalan, G. H. Kim, J. Neubauer, and A. Pesaran, "Models for battery reliability and lifetime," in Battery Congress 2013, Mar. 2013, pp. 1-8.

[53] A. O. David and I. Al-Anbagi, "EVs for frequency regulation: cost benefit analysis in a smart grid environment," IET Elect. Systems in Transp, vol. 7, no. 4, pp. 310-317, Dec. 2017.

[54] S. Downing and D. Socie, "Simple rainflow counting algorithms," Int. J. of Fatigue, vol. 4, no. 1, pp. 31 - 40, Jan. 1982.

[55] B. Xu, A. Oudalov, A. Ulbig, G. Andersson, and D. S. Kirschen, "Modeling of lithium-ion battery degradation for cell life assessment," IEEE Trans. Smart Grid, vol. 9, no. 2, pp. 1131-1140, March 2018.

[56] Roger C. Dugan, Davis Montenegro, Reference Guide: The Open Distribution System Simulator (OpenDSS). EPRI, Jun. 2019.

[57] PJM. (2018) Ancillary services. [Online]. Available: https://www.pjm.com/markets-and-operations/ancillary-services.aspx

[58] — . (2018) Ancillary services. regulation market data. [Online]. Available: http://dataminer2.pjm.com/feed/reg_market_results

[59] Ran Fu, Timothy Remo, and Robert Margolis, "2018 U.S. utility-scale photovoltaics-plus-energy storage system costs benchmark," 2018. 
[60] T. L. Saaty, Fundamentals of Decision Making and Priority Theory With the Analytic Hierarchy Process, ser AHP series. RWS Publications, 2000. [Online]. Available: https://books.google.com.br/books?id=wct10TlbbIUC

[61] M.-B. Shim, M.-W. Suh, T. Furukawa, G. Yagawa, and S. Yoshimura, "Pareto-based continuous evolutionary algorithms for multiobjective optimization," Engineering Computations, vol. 19, pp. 22-48, 022002.

[62] V. Vahidinasab, "Optimal distributed energy resources planning in a competitive electricity market: Multiobjective optimization and probabilistic design," Renewable Energy, vol. 66, pp. 354 - 363, 2014.

[63] G. E. P. Box, G. M. Jenkins, and G. C. Reinsel, Time Series Analysis, 4th ed. New York: Wiley, 2008.

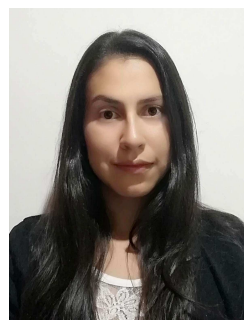

Nataly Banol Arias received the B.Sc. degree in Production Engineering from the Universidad Tecnológica de Pereira, Colombia in 2012, and the M.Sc. and Ph.D. degree in Electrical Engineering from the São Paulo State University (UNESP), Ilha Solteira, Brazil, in 2015 and 2019, respectively. She is currently working as a postdoctoral researcher at the school of electrical and computer engineering at the State University of Campinas (UNICAMP), Campinas, Brazil. Her areas of research are the development of methodologies for the optimization, planning, and control of modern distribution systems including electric vehicles and distributed energy sources.

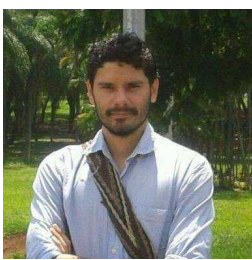

Juan Camilo López received the double B.Sc degrees in electronic engineering and electrical engineering from the Universidad Nacional de Colombia (UNAL), Manizales, Colombia, in 2011 and 2012, respectively. He received his M.Sc. degree in electrical engineering from São Paulo State University (UNESP), in Ilha Solteira, Brazil, in 2015, an the $\mathrm{Ph} . \mathrm{D}$. degree in electrical engineering at the State University of Campinas (UNICAMP), in Campinas, Brazil, in 2019. He is curretly working as a post-doc at the school of electrical and computer engineering at the State University of Campinas (UNICAMP). His research interests include development of methodologies for the optimal operation, planning and monetization of electrical distribution systems, microgrids and distributed energy resources.

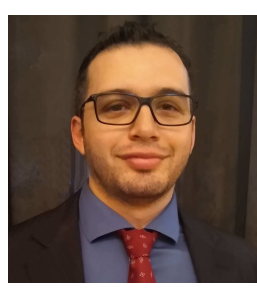

John F. Franco (S'11-M'13-SM'19) received the B.Sc. and M.Sc. degrees in electrical engineering from the Universidad Tecnológica de Pereira, Pereira, Colombia, in 2004 and 2006, respectively, and the $\mathrm{Ph} . \mathrm{D}$. degree in electrical engineering from the São Paulo State University (UNESP), Ilha Solteira, Brazil, in 2012. He is currently a Professor with UNESP, Rosana, Brazil. His area of research is the development of methods for the optimization, planning, and control of electrical power systems.
Marcos J. Rider (S'97-M'06-SM'16) received the B.Sc. (Hons.) and P.E. degrees from the National University of Engineering, Lima, Peru, in 1999 and 2000 , respectively, the M.Sc. degree from the Federal University of Maranhão, Maranhão, Brazil, in 2002; and the Ph.D. degree from the University of Campinas (UNICAMP), Campinas, São Paulo, Brazil, in 2006-all in electrical engineering. From 2010 to 2015, he was Professor at the São Paulo State University (UNESP), Ilha Solteira, São Paulo, Brazil. Currently, he is a Professor in the Department of Systems and Energy at UNICAMP. His areas of research are the development of methodologies for the optimization, planning, and control of electrical power systems, and applications of artificial intelligence in power systems

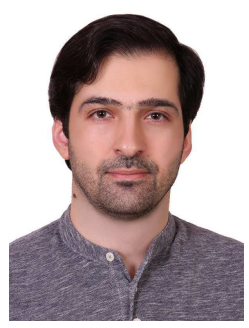

Seyedmostafa Hashemi (S'09, M'16) received the B.Sc. and M.Sc. degree (first class hons.) from Isfahan University of Technology, Isfahan, Iran, in 2006 and 2009, respectively, and the PhD degree from the Technical University of Denmark in 2015, all in electric power engineering. Since 2015, he has been a Postdoc at the Center for Electric Power and Energy, Technical University of Denmark. His research interests include battery and EV services in distribution systems, and grid integration of renewable energy sources. 